\title{
NOT SO FAST! AN INVESTIGATION OF REAL-WORLD SPEEDING BEHAVIORS AND UNDERLYING ATTITUDES
}

\author{
John L. Campbell ${ }^{1}$, Christian Richard ${ }^{1}$, Randolph Atkins ${ }^{2}$, Monica G. Lichty ${ }^{1}$ \& James L. \\ Brown $^{1}$ \\ ${ }^{1}$ Battelle, Seattle, Washington, USA \\ ${ }^{2}$ National Highway Traffic Safety Administration, Washington, D.C., USA \\ Email: campjohn@battelle.org
}

\begin{abstract}
Summary: Although speeding is a major contributor to traffic fatalities, attempts to address this problem have not led to significant reductions in speed-related crashes. In this paper, we describe an investigation of speeding behaviors that was intended to: (1) identify which drivers speed, (2) model the relative roles of situational, demographic, and personality factors in predicting travel speeds, and (3) classify drivers based on their speeding patterns. The speeding behaviors of 88 drivers were recorded over the course of approximately four weeks of naturalistic driving in Seattle WA. Data collected included $1-\mathrm{Hz}$ recordings of vehicle position and speed using a GPS receiver, and responses to survey questions. Regression models were developed to identify predictors of 1) "any" speeding and 2) amount of speeding. Significant predictors included demographic variables such as age and gender, situational factors such as time-of-day and day-of-week, and key personality factors such as attitudes towards reckless driving.
\end{abstract}

DISCLAIMER: The opinions, findings, and conclusions expressed in this publication are those of the authors and not necessarily those of the Department of Transportation or the National Highway Traffic Safety Administration.

\section{INTRODUCTION}

Although speeding is one of the most significant contributors to crash severity and traffic fatalities, attempts to address this problem through a variety of approaches have not led to a significant reduction in speed-related fatalities (National Highway Traffic Safety Administration (NHTSA), 2005). Various studies have found that a range of factors are associated with speeding, including a host of demographic, personality, roadway, environmental, vehicle, and situational variables (see also, Richard et al., 2013). Much of what we believe about speeding, however, reflects data obtained from self-report surveys, "spot speed” engineering data obtained without identifying individual drivers, and crash data/reports - all of which are incomplete and subject to limitations. In short, in order to learn more about why drivers speed and what we can do about it with respect to countermeasures, we need to study the speeding choices that drivers make under natural, everyday driving conditions.

Below, we describe several analyses conducted on naturalistic driving data from 55-60 mph roads to: 1) identify which drivers speed on those roads, 2) model the relative roles of situational, demographic, and personality/attitudinal factors in predicting travel speeds, and 3) classify drivers based their speeding patterns. Future reports will discuss the results of this study in more detail; here we provide an overview of the methodology and a subset of the results. 


\section{METHODS}

This was a naturalistic field study in which volunteer drivers from Seattle, Washington, agreed to have a GPS unit installed in their vehicles for 3 to 4 weeks. The GPS data obtained in the study was used to compare the drivers' speeds to the posted speeds (PSs) associated with the roads that they were driving on at any given point in time. These comparisons between actual speeds and posted speeds formed the basis for the analyses and findings described in this paper. A total of 88 Seattle participants fully completed the study requirements. Table 1 shows the participant demographics.

Table 1. Study design and allocation of participants

\begin{tabular}{|l|c|c|c|c|}
\hline Gender & \multicolumn{2}{|c|}{ Male } & \multicolumn{2}{c|}{ Female } \\
\hline Age & $18-25$ & $35-55$ & $18-25$ & $35-55$ \\
\hline Participants & 21 & 25 & 21 & 21 \\
\hline
\end{tabular}

A summary of the study (Richard, et al., 2012) provides additional details about the methods and results; some methodological lessons learned are described in Richard et al. (2013). Briefly, the threshold for categorizing driving as "speeding" was $10 \mathrm{mph}$ above the posted speed limit. Exposure was also defined and measured; specifically, a new variable was constructed from the data set- “free-flow time" - that reflected the participants' opportunity to speed. To calculate free-flow time, the segments of a trip in which drivers clearly had no opportunity to speed were removed from the measure of trip time/duration. To generate the free-flow driving time variable, we removed all driving that was $5 \mathrm{mph}$ or more below the posted speed (e.g., on a roadway with a posted speed of $35 \mathrm{mph}$, we only included driving time in which the vehicle was traveling at $30 \mathrm{mph}$ or greater). Figure 1 below shows how driving data were extracted from a trip and categorized into free-flow and speeding time.

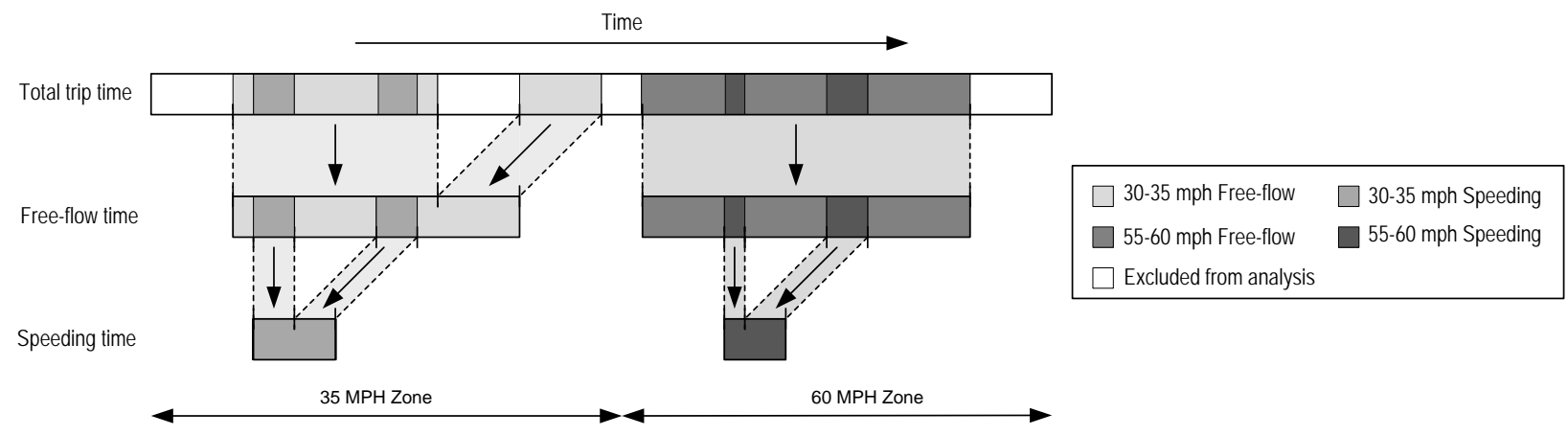

Figure 1. Illustration of how driving data were extracted from a trip (see text)

Personality and attitudinal data were also obtained; specifically, all participants completed the Driver Behavior Questionnaire (DBQ; modified from Reason et al., 1990), Theory of Planned Behavior (TPB) survey measuring driver attitudes, beliefs, and intentions regarding speeding (from Elliott et al., 2005), and a Risky Driving Questionnaire (DeJoy, 1992). 


\section{RESULTS}

Due to space constraints, this paper will only present the results from the Seattle roads with posted speeds of 55 and 60 miles per hour (mph). Table 2 shows the distribution of speeds relative to the posted speed (PS) across all of the Seattle drivers and indicates that the majority of driving occurred within $\pm 5 \mathrm{mph}$ of the posted speed. In the table, "PS +5 " represents driving at speeds between 60-64.99 mph (on a 55 mph road), and the bold line between the "PS-5" (mph) and "PS" categories indicates the posted speed. The speeding that did occur was predominately between 10 and $15 \mathrm{mph}$ above the posted speed. Almost no speeding occurred at speeds faster than $20 \mathrm{mph}$ above the posted speed. There are some differences between demographic groups, but these differences are modest.

Table 2. Percentage of "free-flow" driving time in Seattle relative to the posted speed for each demographic group on 55-60 mph roads

\begin{tabular}{|c|c|c|c|c|c|c|c|}
\hline \multicolumn{8}{|l|}{ Seattle $55-60 \mathrm{mph}$ roads } \\
\hline \multirow{5}{*}{$\begin{array}{r}\text { Older Females } \\
\text { Older Males } \\
\text { Younger Females } \\
\text { Younger Males }\end{array}$} & PS-5 & PS & $\mathrm{PS}+5$ & $\mathrm{PS}+10$ & $\mathrm{PS}+15$ & $\mathrm{PS}+20$ & $\mathrm{PS}+25$ \\
\hline & $34.8 \%$ & $42.4 \%$ & $19.9 \%$ & $2.6 \%$ & $0.3 \%$ & $0.0 \%$ & $0.0 \%$ \\
\hline & $31.6 \%$ & $46.2 \%$ & $17.6 \%$ & $3.6 \%$ & $0.7 \%$ & $0.1 \%$ & $0.0 \%$ \\
\hline & $25.1 \%$ & $39.9 \%$ & $28.2 \%$ & $5.9 \%$ & $0.7 \%$ & $0.1 \%$ & $0.0 \%$ \\
\hline & $24.1 \%$ & $42.4 \%$ & $27.3 \%$ & $5.1 \%$ & $0.8 \%$ & $0.2 \%$ & $0.0 \%$ \\
\hline Overall & $28.9 \%$ & $42.8 \%$ & $23.1 \%$ & $4.4 \%$ & $0.7 \%$ & $0.1 \%$ & $0.0 \%$ \\
\hline
\end{tabular}

\section{Identifying Which Drivers Speed}

Using a binary variable that indicated whether or not any speeding occurred on a given trip, a logistic regression analysis was conducted to address the question: who is speeding? Two sets of analyses were conducted: (1) an analysis using demographic and trip (time-of day, day-of-week) variables only, and (2) an analysis that included personality inventory variables.

A summary of the logistic regression models conducted with the demographic and trip variables is shown in Table 3 below. This analysis provided information about the relative odds for significant predictors (i.e., the odds of there being any speeding in Group 1 was X times greater than in Group 2). In each analysis, Older Females were used as the comparison group for the other demographic groups because they were typically less likely to speed or to speed as frequently as the other groups. We also calculated the odds ratio comparisons between each group separately to show which groups differed from one another. Because this was an exploratory study - and because we wanted to compare results across analyses - we have also included some variables in the tables that are borderline statistically significant at $\mathrm{p}<.10$.

A general pattern in the logistic regression models is that younger drivers were more likely than older drivers to have any speeding in a trip. Table 4 provides all the odds ratios for the demographic variables. 
Table 3. Summary of the logistic regression models

\begin{tabular}{|c|c|}
\hline & Seattle 55-60 mph \\
\hline $\begin{array}{l}\text { Demographic } \\
\text { Variables }\end{array}$ & $\begin{array}{l}\text { - Younger Males were more likely to have any speeding than Older Females** } \\
\text { - Younger Males were more likely to have any speeding than Older Males* } \\
\text { - Younger Females were more likely to have any speeding than Older Females** } \\
\text { - Younger Females were more likely to have any speeding than Older Males** }\end{array}$ \\
\hline Trip Variables & $\begin{array}{l}\text { - Weekend driving more likely to have any speeding that Weekday driving** } \\
\text { - Morning rush hours (5am-9am) were more likely to have any speeding than driving between 12am- } \\
\text { 5am*** } \\
\text { - Driving between 9am-3pm more likely to have any speeding than during morning rush hours }{ }^{\dagger} \\
\text { - Morning rush hours more likely to have any speeding than driving between } 7 \mathrm{pm}-12 \mathrm{am}^{\dagger}\end{array}$ \\
\hline
\end{tabular}

${ }^{* * *} p<.001 ;{ }^{* *} p<.01 ;{ }^{*} p<.05 ;{ }^{\dagger} p<.10$

Table 4. Comparison of odds ratios across demographic groups

\begin{tabular}{|l|c|c|c|}
\hline Demographic Group & $\begin{array}{c}\text { vs. Older Females } \\
\text { Odds Ratio [95\% CI] }\end{array}$ & $\begin{array}{c}\text { vs. Older Males } \\
\text { Odds Ratio [95\% CI] }\end{array}$ & $\begin{array}{c}\text { vs. Younger Females } \\
\text { Odds Ratio [95\% CI] }\end{array}$ \\
\hline Older Males & $1.25[0.485-3.21]$ & & \\
\hline Younger Females & $4.53[1.70-12.02]^{* *}$ & $3.63[1.41-9.32]^{* *}$ & \\
\hline Younger Males & $4.02[1.52-10.68]^{* *}$ & $3.22[1.25-1.92]^{*}$ & $0.89[0.37-2.35]$ \\
\hline
\end{tabular}

${ }^{\star * \star} p<.001 ;{ }^{* \star} p<.01 ;{ }^{*} p<.05 ; \mathrm{tp}<.10$

\section{Model Situational, Demographic, and Personality/Attitudinal Predictors of Speeding}

A separate set of regression analyses were conducted to identify driver attitudes, motivations, and beliefs that might predict driver speeding behavior. Because of the large number of questions included in the personal inventory $(\mathrm{N}=111)$, we conducted factor analyses to create factor scores for groups of related variables. Separate factor analyses were run on the three primary personal inventory instruments used, with 10 separate factors identified. The four factors relevant to the "Seattle 55-60 mph" analyses are described in Table 5 below. These factors were primarily based on questions from either the DBQ (Bad Driving factor; Reason et al., 1990), or speeding questions from the Theory of Planned Behavior survey (other 3 factors; Elliott et al., 2005).

Table 5. Names and descriptions of factors obtained in the factor analysis that were relevant to the "Seattle 55-60 $\mathrm{mph}$ " analyses

\begin{tabular}{|l|l|}
\hline \multicolumn{1}{|c|}{ Factor Name } & \multicolumn{1}{c|}{ Factor Description } \\
\hline Bad Driving & Higher factor loadings represented items that include driving mistakes or apparent lack of skill. \\
\hline $\begin{array}{l}\text { Behavioral and Control } \\
\text { Beliefs related to } \\
\text { Temptation to speed } \\
\text { (BCB-Temptation) }\end{array}$ & $\begin{array}{l}\text { This factor incorporates a subset of control beliefs and behavioral beliefs. These items seem to } \\
\text { be related to emotional or impulsive reasons for speeding. Higher factor loadings are related to } \\
\text { resisting temptation to speeding, with negative values indicating negative attitudes toward } \\
\text { reasons for speeding }\end{array}$ \\
\hline Subjective Norms & $\begin{array}{l}\text { This factor includes mostly items that reflect how people who are important to the driver feel } \\
\text { about speeding. Higher factor loadings indicate that important people have a larger influence } \\
\text { on the driver's behavior. }\end{array}$ \\
\hline $\begin{array}{l}\text { Control Beliefs related to } \\
\text { Opportunity to speed } \\
\text { (CB-Opportunity) }\end{array}$ & $\begin{array}{l}\text { This factor contained a subset of control beliefs that mostly reflected situations in which there } \\
\text { was limited opportunity to speed (i.e., traffic calmed areas), but with some clear exceptions } \\
\text { (e.g., on straight long roads). The higher the loadings on this factor, the more likely a driver is } \\
\text { to avoid speeding when there is limited opportunity to do so. }\end{array}$ \\
\hline
\end{tabular}


Using the base model, which included only the control and dependent variables, all 10 factor scores (including the six not described above in Table 5) were added to the model with the corresponding speeding-related dependent variables. Interestingly, the findings changed somewhat when factor score variables constructed from the personality questions were included in the analysis. Specifically, many of the demographic effects were no longer significant, in favor of some key beliefs and attitudinal factors. A summary of the logistic regression models conducted with demographic, trip, and factor-score variables is shown in Table 6 below.

Table 6. Summary of the logistic regression models

\begin{tabular}{|l|c|}
\hline \multicolumn{1}{|c|}{ Significant Predictor } & \multicolumn{1}{c|}{ Description } \\
\hline Demographic Variables & - Younger Females were more likely to have any speeding than Older Females*** \\
\hline $\begin{array}{l}\text { Trip Variables (MR=Morning Rush } \\
\text { Hour) }\end{array}$ & $\begin{array}{l}\text { a } \\
- \text { Weekend driving more likely to have any speeding that Weekday driving** } \\
- \text { Morning rush hours (5am-9am) were more likely to have any speeding than } \\
\text { driving between 12am-5am*** }\end{array}$ \\
\hline $\begin{array}{l}\text { Factor score variables associated } \\
\text { with increased odds of any speeding }\end{array}$ & $\begin{array}{l}\text { - Bad Driving (More frequently making driving mistakes that show a lack of } \\
\text { skill.)* }\end{array}$ \\
\hline $\begin{array}{l}\text { Factor score variables associated } \\
\text { with decreased odds of any speeding }\end{array}$ & $\begin{array}{l}\text { BCB-Temptation (Being more likely to drive within the speed limit in situations } \\
\text { when roadway factors provide temptation to speed.)*** }\end{array}$ \\
& $\begin{array}{l}\text { Subjective Norms (Stronger agreement that people who are important to them } \\
\text { would approve of them driving within the speed limit.)* }\end{array}$ \\
& $\begin{array}{l}\text { CB-Opportunity (Being more likely to drive within the speed limit when they } \\
\text { generally do not have a good opportunity to speed.)* }\end{array}$ \\
\hline
\end{tabular}

${ }^{* \star \star} p<.001 ;{ }^{* \star} p<.01 ;{ }^{*} p<.05 ;{ }^{\dagger} p<.10$

\section{Classifying Drivers Based their Speeding Behavior}

In an attempt to explore the possibility that speeding taxonomies exist and can be measured, information about driver speeding patterns was obtained using two different speeding measures: 1) the percent of trips with any speeding, and 2) the average percent of time speeding within a trip. These measures provide complementary information about driver speeding since they differently reflect persistent and situational elements of speeding behavior. Using this approach, the corresponding scatterplot for the Seattle 55-60 mph speed bands are shown in Figure 2 below (left side). Individual drivers are plotted as separate colored circles, and the size of each circle corresponds to the number of trips with free-flow driving for that driver. Note that the text that indicates the number of points at the origin (i.e., " $\mathrm{N}=5$ ") represents the number of drivers that had no speeding in that speed band.

For the Seattle 55-60 mph roads, most drivers had at least some speeding on a high percentage of their trips, but the amount of speeding during the trips was relatively low. However, there is a small group of drivers (mostly males) who engage in lots of per-trip speeding on a large number of trips. Richard et al. (2012) examines these taxonomies across other speed bands in Seattle and Texas, and describes some findings with respect to the existence - and nature - of speeding taxonomies. The right side of Figure 2, showing the scatter plot for the 30-35 mph speed band, provides a useful illustration of this approach. On these lower-speed roads, there is a group of mostly older male drivers that rarely speed (shown near the Y-axis); but when they did, it was for much of their trip - these drivers may be situational speeders (e.g., those who only speed when late). There is also another group in the top right that speeds often, and for much of their trips these drivers may be habitual speeders. 
Scatter plot: Seattle 55-60 mph

- Few trips with free-flow $(<5)$

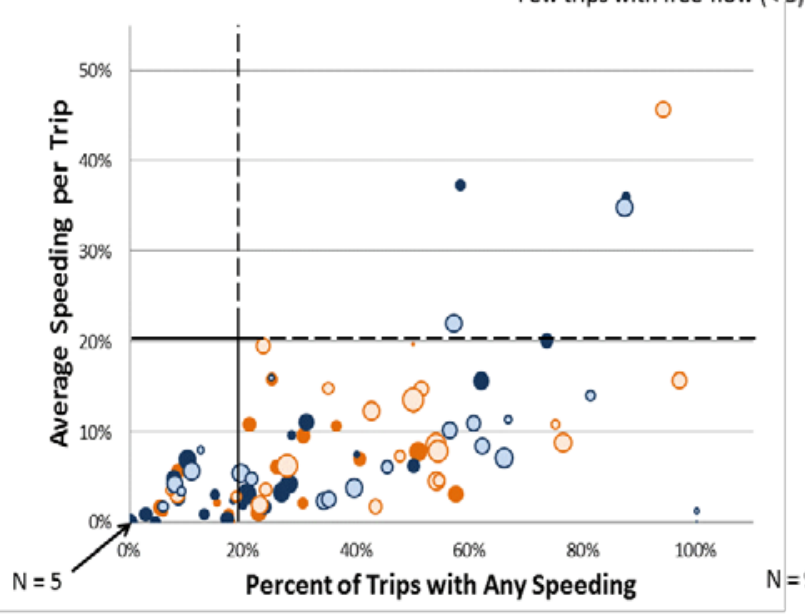

Scatter plot: Seattle 30-35 mph

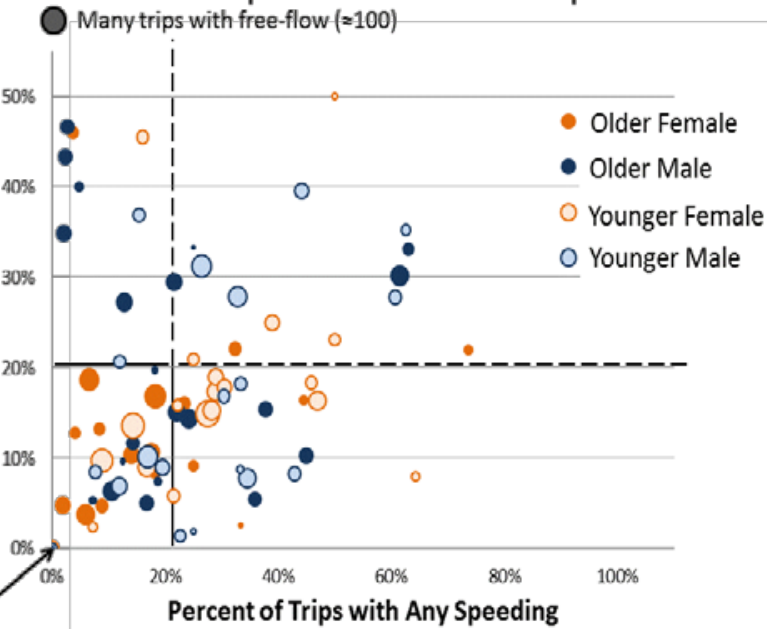

Figure 2. Seattle 55-60 mph and 30-35 mph: Scatterplots of speeding behavior

\section{CONCLUSIONS}

The results from the Seattle 55 and 60 mph roads paint a fascinating picture regarding the relative importance of demographics, situational factors, and personality in predicting speeding behaviors. In short, there is considerable variability in speeding across situational/trip-specific factors, demographic groups, and individual driver/personal characteristics. Some key trends observed in the results reported above include the following:

- It is relatively common for drivers to have at least some speeding on a given trip, and overall - about 5\% of free flow driving on Seattle's 55 and 60 mph roads occurred at 10 mph or more above the speed limit. However, there are some drivers that rarely speed.

- There are very clearly some trip factors that influence drivers' decision to speed, including day-of-week and time-of-day factors that may be related to opportunistic (e.g., less congested roadways) and situational (e.g., late for work) conditions.

Conclusions directly related to the study objectives are listed below:

Which Drivers Speed: With respect to absolute amounts of speeding, younger drivers are speeding the most, with about twice the speeding as older drivers.

Predictors of Speeding: While the younger drivers were more likely to speed than the older drivers (about 3-4 times more likely), certain underlying habits, beliefs and attitudes (like poorer driving skills, speeding when faced with the temptation or opportunity to speed, and being less influenced by the disapproval of others towards speeding) were strongly associated with propensity to speed and were generally better predictors of speeding than age or gender. This doesn't mean that age is irrelevant or that speeding countermeasures targeted at young drivers will be ineffective, but it underscores the complexity of speeding and highlights the importance of considering motivational factors as part of countermeasure development and implementation.

Classifying Speeders: The scatter plots shown in Figure 2 above show clear evidence for different speeding typologies (i.e., differences across drivers with respect to the percent of trips with any speeding, the average percent of time speeding within a trip), and provide the basis for 
a new taxonomy of speeding behaviors, as shown below in Figure 3. While the zone boundaries (set at 20\%) are somewhat arbitrary, the taxonomies are based on observed behaviors that provide insights into the different reasons for speeding across drivers.

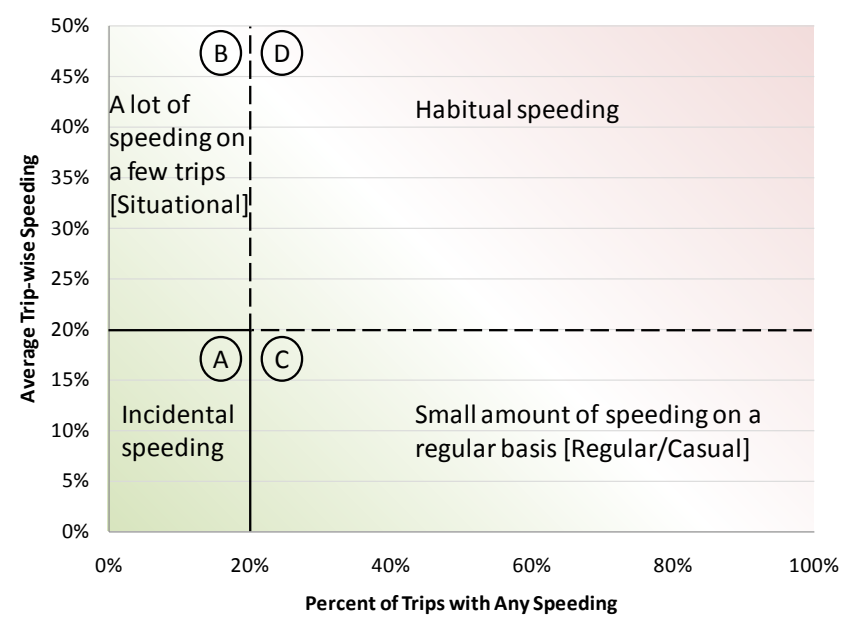

Figure 3. Types of speeding based on the scatterplot of the primary dependent measures

\section{ACKNOWLEDGMENT}

This study was funded by the National Highway Traffic Safety Administration (NHTSA) under Contract Number DTNH22-06-D-0040. Dr. Randolph Atkins was the NHTSA Task Order Manager for this project. The authors gratefully acknowledge the efforts and contributions of Diane Williams, Ashley Loving, Elizabeth Jackson, Ta Liu, and Dale Rhoda of Battelle, and of the following researchers at Texas Transportation Institute: Lee Ann Bell, Katie Connell, Laura Higgins, and Marshall Ward. Dr. John D. Lee of the University of Wisconsin and Dr. Linda Boyle of the University of Washington also provided invaluable assistance throughout the effort.

\section{REFERENCES}

DeJoy, D. M. (1992). An examination of gender differences in traffic accident risk perception. Accident Analysis and Prevention, 24, 237-246.

Elliott, M.A., Armitage, C.J., and Baughan, C.J. (2005). Exploring the beliefs underpinning drivers' intentions to comply with speed limits. Transportation Research: Part F 8, 459-479.

National Highway Transportation Safety Administration (NHTSA). (2005). National forum on speeding. Summary report (Report No. DOT HS 809 963). Washington, DC: Author.)

Reason, J., Manstead, A., Stradling, S., Baxter, J., and Campbell, K. (1990). Errors and violations on the roads: a real distinction? Ergonomics, 33(10/11), 1315-1332.

Richard, C. M., Campbell, J. L., Brown, J. L., Lichty, M. G., Chrysler, S., and Atkins, R. (2013). Investigating speeding behavior using naturalistic approaches: Methodological lessons learned. Proceedings of the 92nd Annual Meeting of the Transportation Research Board.

Richard, C. M., Campbell, J. L., Lichty, M. G., Brown, J. L., Chrysler, S., Lee, J. D., Boyle, L., and Reagle, G. (2012). Motivations for speeding. Volume I Summary Report (DOT HS 811 658). Washington, DC: National Highway Traffic Safety Administration. 